\title{
Rust Layer Formed on Low Carbon Weathering Steels with Different Mn, Ni Contents in Environment Containing Chloride Ions
}

\author{
Gui-qin FU ${ }^{1 *}$, Miao-yong $\mathrm{ZHU}^{1}$, Xin-liang GAO ${ }^{1,2}$ \\ ${ }^{1}$ School of Metallurgy, Northeastern University, Shenyang 110819, China \\ ${ }^{2}$ College of Mechanical Engineering, Yanshan University, Qinghuangdao 066004, China \\ crossref http://dx.doi.org/10.5755/j01.ms.22.4.12844
}

Received 05 August 2015; accepted 11 March 2016

\begin{abstract}
The rusting evolution of low carbon weathering steels with different $\mathrm{Mn}, \mathrm{Ni}$ contents under a simulated environment containing chloride ions has been investigated to clarify the correlation between $\mathrm{Mn}, \mathrm{Ni}$ and the rust formed on steels. The results show that $\mathrm{Mn}$ contents have little impact on corrosion kinetics of experimental steels. Content increase of $\mathrm{Ni}$ both enhances the anti-corrosion performance of steel substrate and the rust. Increasing $\mathrm{Ni}$ content is beneficial to forming compact rust. Semi-quantitative XRD phase analysis shows that the quantity ratio of $\alpha / \gamma^{*}\left(\alpha-\mathrm{FeOOH} /\left(\gamma-\mathrm{FeOOH}+\mathrm{Fe}_{3} \mathrm{O}_{4}\right)\right)$ decreases as $\mathrm{Mn}$ content increases but it increases as $\mathrm{Ni}$ content increases. Ni enhances rust layer stability but Mn content exceeding $1.06 \mathrm{wt} . \%$ is disadvantageous for rust layer stability. The content increase of Mn does not significantly alter the parameters of the polarization curve. However, as Ni contents increases, $E_{\text {corr }}$ has shifted to the positive along with decreased $i_{\text {corr }}$ values indicating smaller corrosion rate especially as $\mathrm{Ni}$ content increases from $0.42 \mathrm{wt} . \%$ to $1.50 \mathrm{wt} . \%$.

Keywords: rust layer, low carbon weathering steel, polarization, atmospheric corrosion.
\end{abstract}

\section{INTRODUCTION}

It is widely understood that atmospheric corrosion of steels is affected by alloy elements and surrounding environments. As corrosion product, the composition and structure of rust layer has a remarkable effect on the corrosion rate of steels $[1,2]$. The small addition of alloy elements in weathering steels facilitates the formation of a shielding rust layer to hinder further corrosion, which promotes the application in manufacture of bridges [3-7]. Besides corrosion resistance performance, good comprehensive properties are needed for the bridge weathering steels such as mechanical properties and weld ability.

It is generally believed that high carbon content deteriorates the weld ability of steels, to avoid this, less carbon was added and sometimes Mn was chosen as economical alloy to increase the mechanical strength. Hao et al. and $\mathrm{Ke}$ et al. $[8,9]$ reported that $\mathrm{Mn}$ substituted $\mathrm{Fe}$ in the location of the $\mathrm{Fe}_{3} \mathrm{O}_{4}$ crystal so that the rust could repel the penetration of anions in chloride ions containing condition. Gao et al. [10] believed that Mn could facilitate the formation of $\alpha-\mathrm{FeOOH}$ to increase the stability of rust layer in marine atmospheric environment. Yamashita et al. and Katayama et al. [11,12] indicated that in marine atmospheric environment $\mathrm{Mn}$ had no evident influence on corrosion resistant performance. Currently, the existing controversy on the influence of $\mathrm{Mn}$ on anti-corrosion property in marine atmosphere called further research. Ni Nishimura et al. [13] indicated that spinel oxide in the rust formed when $\mathrm{Ni}$ substituted $\mathrm{Fe}$ which favourably forms a compact rust layer. Chen et al. and Kimura et al. [14, 15] clarified that weathering steels containing $3 \mathrm{wt} . \%$ or more

\footnotetext{
${ }^{*}$ Corresponding author. Tel.: +86-24-83671706; fax: +86-24-23906316 E-mail address: fugq@smm.neu.edu.cn (G. Fu)
}

than 4 wt.\% Ni exhibited good anti-corrosion property in an environment containing chloride ions due to the formation of $\mathrm{Fe}_{2} \mathrm{NiO}_{4}$ which gave cation-selectivity to the rust which hinders the entering of anions such as chloride ions. Many studies have been focused on the beneficial effect on $\mathrm{Ni}$ content with high content as $3 \mathrm{wt} . \%$ or more. However, increasing $\mathrm{Ni}$ content will increase the cost of steel products. The rusting evolution of weathering steels with different $\mathrm{Ni}$ contents under a simulated environment containing chloride ions need further study.

As a result, the aim of the present paper is to determine the rusting evolution of low carbon weathering steels influenced by contents of $\mathrm{Mn}$ and $\mathrm{Ni}$. To achieve this purpose, the corrosion evolution of steels containing altering $\mathrm{Mn}$, $\mathrm{Ni}$ contents submitted to a simulated environment containing chloride ions was studied by corrosion weight loss, some appropriate analysis techniques (SEM, XRD) and polarization curves.

\section{EXPERIMENTAL DETAILS}

\subsection{Preparation of samples}

The samples with the size of $30 \mathrm{~mm} \times 20 \mathrm{~mm} \times 5 \mathrm{~mm}$ were cut from experimental steels, which were vacuuminducted then hot rolled. The chemical composition is given in Table 1.

Table 1. Chemical composition of experimental steels (wt.\%)

\begin{tabular}{|c|c|c|c|c|c|c|}
\hline Item & 1 & 2 & 3 & 4 & 5 & 6 \\
\hline $\mathrm{C}$ & 0.038 & 0.030 & 0.025 & 0.035 & 0.040 & 0.035 \\
\hline $\mathrm{Mn}$ & 0.75 & 1.06 & 1.43 & 0.75 & 0.71 & 0.70 \\
\hline $\mathrm{Ni}$ & 0.22 & 0.24 & 0.22 & 0.42 & 1.50 & 3.44 \\
\hline $\mathrm{P}$ & 0.020 & 0.025 & 0.021 & 0.020 & 0.022 & 0.023 \\
\hline $\mathrm{S}$ & 0.006 & 0.007 & 0.006 & 0.007 & 0.006 & 0.007 \\
\hline $\mathrm{Si}$ & 0.21 & 0.22 & 0.23 & 0.22 & 0.23 & 0.23 \\
\hline $\mathrm{Cr}$ & 0.48 & 0.47 & 0.50 & $\ldots$ & $\ldots$ & $\ldots$ \\
\hline $\mathrm{Cu}$ & 0.31 & 0.30 & 0.32 & 0.31 & 0.30 & 0.29 \\
\hline
\end{tabular}


All samples were ground by 4000 grit $\mathrm{SiC}$ papers, cleaned using the acetone, rinsed by distilled water, and finally rinsed with alcohol. Each of the samples was weighted after drying, and the net weight was recorded as $W_{0}(\mathrm{~g})$.

\subsection{Wet/dry cyclic corrosion test}

The corrosion behaviour of the experimental steels in the environmental containing chloride ions was simulated by an alternate wet/dry corrosion test. Each wet/dry cycle lasted for $80 \mathrm{~min}$ which consists of immersing the steel samples into $0.1 \mathrm{~mol} / \mathrm{L} \mathrm{NaCl}$ solution at $42{ }^{\circ} \mathrm{C}$ for $18 \mathrm{~min}$, and drying the samples at $45^{\circ} \mathrm{C},(32 \pm 2) \%$ relative humidity (RH) for $62 \mathrm{~min}$. Subsequently, the samples were taken out for analysis after 2, 4, 6, 10 and 14 days corrosion respectively, for weight loss measurement and further SEM, XRD studies. The rusted samples were immersed and cleaned in a solution $(500 \mathrm{~mL}$ hydrochloric acid $+500 \mathrm{~mL}$ distilled water $+20 \mathrm{~g}$ hexamine) by the ultrasonic cleaner to remove the rust. Subsequently, the steel samples were rinsed using the anhydrous alcohol, dried in air and finally weighted. The corrosion depth and average corrosion rate of the samples can be calculated by the following equations:

$$
\begin{aligned}
& d_{c}=\left(W_{0}-W_{1}\right) /(\rho \cdot S) ; \\
& v_{c}=\left(K \cdot d_{c}\right) / T,
\end{aligned}
$$

where $d_{c}$ refers to the corrosion depth in $\mu \mathrm{m} ; W_{l}$ refers to the weight after corrosion in $\mathrm{g} ; S$ refers to surface area on the specimen in $\mathrm{cm}^{2} ; \rho$ is the density of steel in $\mathrm{g} / \mathrm{cm}^{3} ; v_{\mathrm{c}}$ is corrosion rate in mm/year; $K$ is constant $8.76 \times 10^{4}$, and $T$ refers to corrosion time.

\subsection{Rust analysis}

Powered rust was scraped from the surface of the steel samples with a razor blade for the X-ray diffraction (XRD) study using a $\mathrm{Cu}$ target. The scanning speed maintained $2 \% \mathrm{~min}$ and the $2 \theta$ angle was from $10^{\circ}$ to $70^{\circ}$. The surface morphologies of rust layers were characterized by SEM (Shimazu SSX-500).

\subsection{Electrochemical measurements}

Auto electrochemical workstation was adopted to carry out the polarization measurements. The exposed area of the rusted samples used as working electrode was controlled strictly at $1 \mathrm{~cm}^{2}$ while a large area platinum and a saturated calomel electrode (SCE) were served as the counter electrode and the reference electrode respectively. The polarization curves were got at constant scanning rate of $10 \mathrm{mV} / \mathrm{min}$ at room temperature $\left(25 \pm 1{ }^{\circ} \mathrm{C}\right)$ and $0.1 \mathrm{~mol} / \mathrm{L}$ $\mathrm{NaCl}$ aqueous solution was served the electrolyte.

\section{RESULTS AND DISCUSSION}

\subsection{Corrosion kinetics}

Fig. 1 illustrates the evolution of corrosion depths of steel samples altering with time in a simulated environment containing chloride ions. Clearly the corrosion depths increased as corrosion proceeded during the whole test. Moreover, the corrosion depths of samples with less Ni contents were significantly bigger than that of the samples containing more Ni contents. However the corrosion depths of samples with different $\mathrm{Mn}$ contents remained similar. It indicated that $\mathrm{Mn}$ element in the experimental steels had no evident influence on the corrosion kinetics of steels.

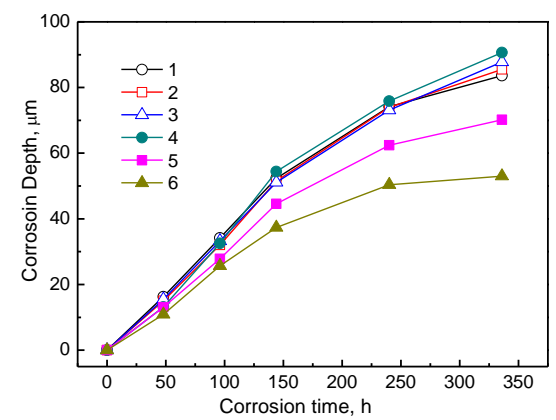

Fig. 1. Corrosion depths of samples altering with time

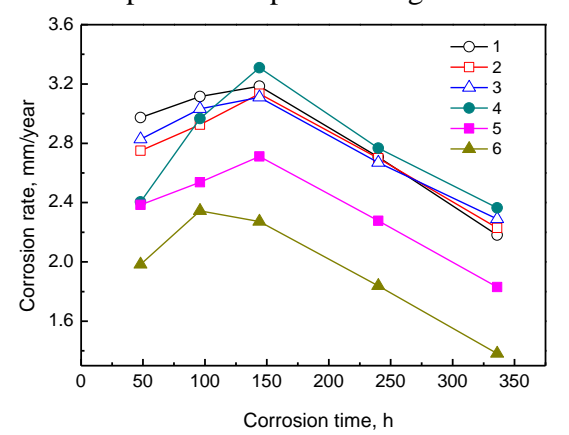

Fig. 2. Mean corrosion rate of samples changes with time

Fig. 2 displays the trend of mean corrosion rate of different samples altering with time. Generally, the average corrosion rate first increased slightly then decreased evidently as corrosion time prolonged. In the initial stage, the average corrosion rate increased from $48 \mathrm{~h}$ to $144 \mathrm{~h}$ since in this stage the steel samples were getting rusty but the continuous rust layer did not form to shield the bare steel. In this stage, the corrosion rate was mainly controlled by the reaction between steel substrate and the atmosphere, namely the microstructure of the steel substrate plays a key role. During this stage, the mean corrosion rate of samples with less Mn was bigger than that of samples containing more Mn. As studied in literature [8], the content increase of $\mathrm{Mn}$ helped to refine the grain size, meanwhile, the microstructure of steels with high $\mathrm{Ni}$ content of 3.44 wt.\% was composed of bainite and ferrite. So we can deduce that the content increase of both $\mathrm{Mn}$ and Ni helped to increase the anti-corrosion performance with more refined microstructure composed of bainite and ferrite.

Comparing the corrosion depth and corrosion rate vs. time of steels No. 1-3 with different Mn contents with that of steels No. $4-6$ with different Ni contents, we could find that $\mathrm{Mn}$ could influence the initial corrosion through affecting the microstructure of steel substrate but had no evident effect on the corrosion kinetics when the continuous rust formed. As for $\mathrm{Ni}$, corrosion depths and mean corrosion rate of samples containing less $\mathrm{Ni}$ were evidently bigger than that of samples containing more $\mathrm{Ni}$ and as time prolonged, the distinction for mean corrosion rate remained unchanged between different $\mathrm{Ni}$-containing steels. This indicated that altering $\mathrm{Ni}$ content could not only influence the initial corrosion stage through affecting 
the microstructure of steel substrate but also affect the long term corrosion kinetics through influencing the rust layer and the polarization curve which will be discussed in detail later.

\subsection{Rust characterization}

Fig. 3 illustrates the morphologies of outer rust surfaces on samples No. $1-3(\mathrm{a}-\mathrm{c})$ corroded for $144 \mathrm{~h}$, and samples No. $1-3(\mathrm{~d}-\mathrm{f})$ corroded after $336 \mathrm{~h}$. As seen from Fig. 3, after $144 \mathrm{~h}$, granular continuous rust layer formed on steel substrate but there still existed hollows and cracks. After $336 \mathrm{~h}$, except for No. 3 steel containing 1.43 wt.\% Mn, the compactness of rust was enhanced. Under the same corrosion time, the compactness of rust formed on sample No. 2 was the most, which indicated that altering Mn content whinin a certain level facilitated the formation of denser rust with more refined grain.
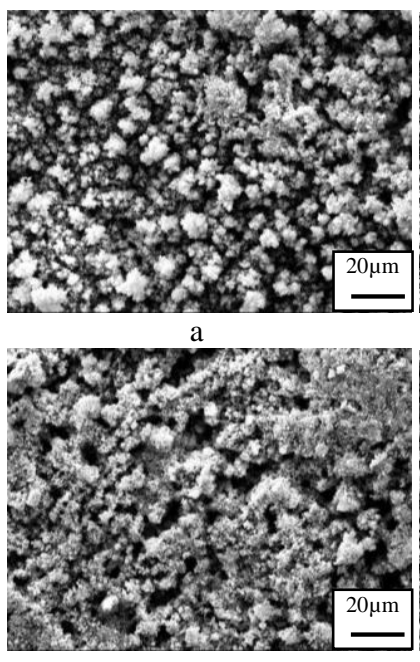

c

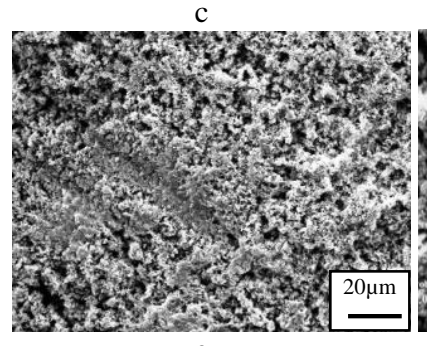

e

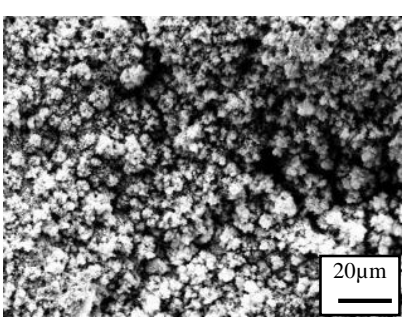

b

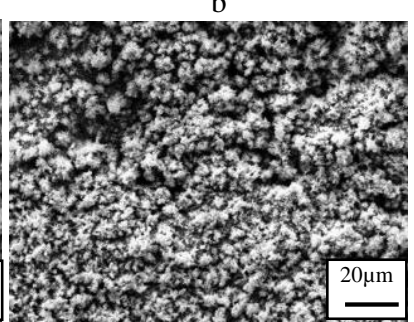

d

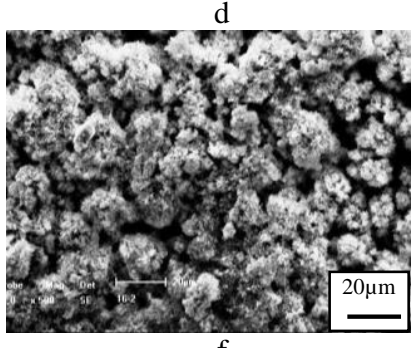

f
Fig. 3. Morphologies of outer rust surfaces on samples No.1-3(ac) corrupted for $144 \mathrm{~h}$, and samples No.1-3(d-f) corrupted for $336 \mathrm{~h}$

Fig. 4 displays the morphologies of outer rust surfaces on samples No. 4-6 $(\mathrm{a}-\mathrm{c})$ corroded after $144 \mathrm{~h}$, and samples No. $4-6(\mathrm{~d}-\mathrm{f})$ corroded after $336 \mathrm{~h}$. Clearly, the compactness of rust on samples increaed as time prolonged. As seen from Fig.4, after $144 \mathrm{~h}$ granular continuous had formed on steel substrates with different $\mathrm{Ni}$ contents, however cracks and hollows still exsited. Subsequently after $336 \mathrm{~h}$, the compactness of the rust was enchanced. Comparing the compacness of the rust, we could find that the rust on steel containing more $\mathrm{Ni}$ appeared to be evidently more tight than that on steel containing less $\mathrm{Ni}$, it indicated that $\mathrm{Ni}$ enchanced the compactness of rust on the steel samples with smaller grain size which obstructed the corrosion media such as chloride ions and $\mathrm{O}_{2}$ in the atmosphere from entering into the steel substrate hence the protetive ability of the rust was improved.
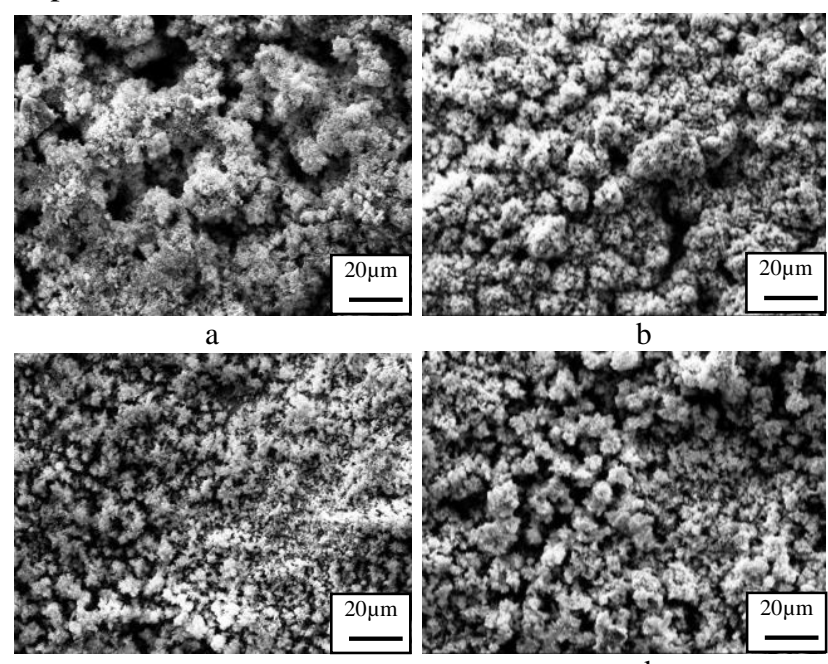

b

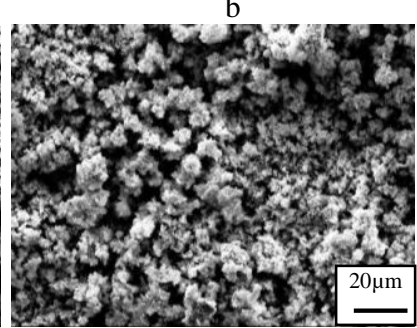

d
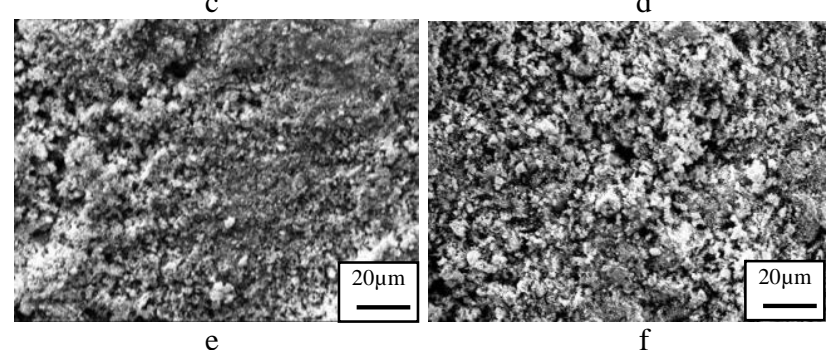

Fig. 4. Morphologies of outer rust surfaces on samples No. 4-6 (a-c) corrupted for $144 \mathrm{~h}$, and samples No. $4-6(d-e)$ corrupted for $336 h$

By comparing the morphologies of rust formed on steel samples with different contents of $\mathrm{Mn}$ and $\mathrm{Ni}$, as seen in Fig. 3 and Fig. 4, it could be deduced that in the range of $0.75 \mathrm{wt} . \%$ and $1.06 \mathrm{wt} \%$, increasing the content of $\mathrm{Mn}$ facilitated the formation of more dense and thin rust, while further increasing the content of $\mathrm{Mn}$ the rust became less dense and protective. $\mathrm{Ni}$ made evident change on the morphologies of the rust formed on different samples. As $\mathrm{Ni}$ content increased, the compactness of the rust layers on steel samples was increased evidently. It is believed that dense rust with less cracks and pores could hinder the further entering of $\mathrm{Cl}^{-}$and $\mathrm{O}_{2}$ consequently the reaction between the steel substrate and chloride ions could be suppressed. As a result, Ni content increase could protect the steel substrate and increase the corrosion resistance however the increase of Mn content exceeding 1.06 wt.\% worsen the protective ability of the rust.

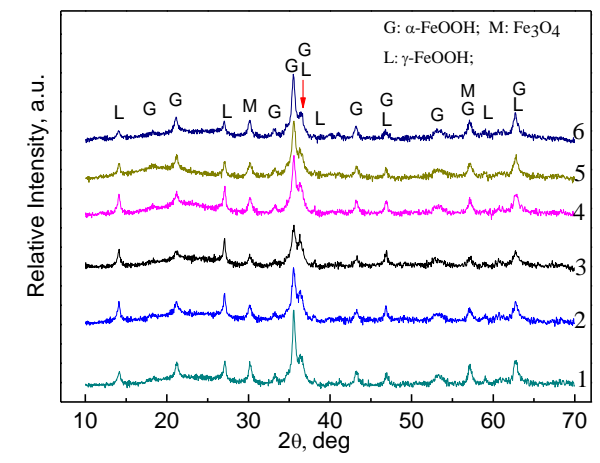

Fig. 5. XRD patterns of rust layers formed on steel samples corrupted for $336 \mathrm{~h}$ 


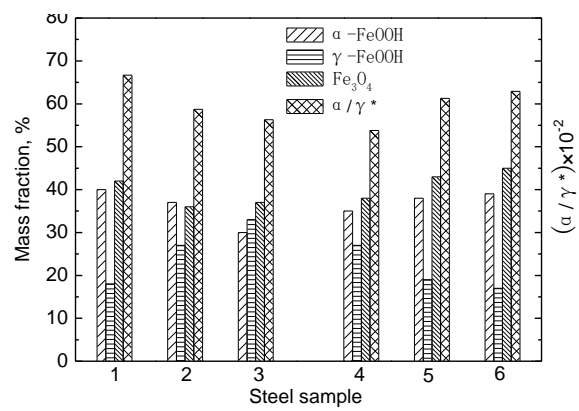

Fig. 6. Semi-quantitative characterization of phases in rust layers formed on steels corrupted for $336 \mathrm{~h}$

Fig. 5 displays the rust phases constitution of the experimental steels studied by XRD. Phases of $\alpha-\mathrm{FeOOH}$, $\gamma$-FeOOH and $\mathrm{Fe}_{3} \mathrm{O}_{4}$ are detected. To analyse the influence of alloy elements on the content of different corrosion products in rust layers, the rust constitution by semiquantitative determination of the rust formed on steel samples corrupted for $336 \mathrm{~h}$ is illustrated in Fig. 6.

Since $\gamma$-FeOOH is an active phase, which could transfer to other phases such as $\delta$-FeOOH, $\mathrm{Fe}_{3} \mathrm{O}_{4}$ and $\alpha$ $\mathrm{FeOOH}$. During this process, the volume of the rust will change resulting the appearance of cracks and hollows, which facilitate the entering of ions from outer side like $\mathrm{H}_{2} \mathrm{O}, \mathrm{O}_{2}, \mathrm{Cl}^{-}$and so on. When the ions reached at the substrate new reaction between them will happen, as a result more steel substrate will be corrupted and the rust of steel samples became less protective. $\mathrm{Fe}_{3} \mathrm{O}_{4}$ is also an active phase which could transfer to $\alpha$-FeOOH although it is more stable than $\gamma-\mathrm{FeOOH}$. In this process, volume change will also happen in the rust of steel samples. Among the phases in the rust, $\alpha-\mathrm{FeOOH}$ is the most stable one in thermodynamics. Kamimura et al. [16] believed that the ratio of $\alpha / \gamma^{*}$ could be regarded as an important index of protection performance of the rust. The rust with bigger $\alpha / \gamma^{*}$ ratio has better protective ability and higher stability. Here, $\alpha$ refers to quantity of $\alpha-\mathrm{FeOOH}$ which has the highest thermodynamic stability among $\alpha-\mathrm{FeOOH}, \gamma$ $\mathrm{FeOOH}$ and $\mathrm{Fe}_{3} \mathrm{O}_{4}, \gamma^{*}$ refers to the quantity value of $(\gamma$ $\mathrm{FeOOH}+\mathrm{Fe}_{3} \mathrm{O}_{4}+\mathrm{Fe}_{2} \mathrm{O}_{3}$ ).

It could be noted that in Fig. 6, with increasing Mn content, the content of $\alpha-\mathrm{FeOOH}$ reduced first slightly then obviously, the content of $\mathrm{Fe}_{3} \mathrm{O}_{4}$ first decreased then increased while the content of $\gamma$-FeOOH increased evidently on the rust of samples corrupted for $336 \mathrm{~h}$. When the content of Mn was raised, the ratio of $\alpha / \gamma^{*}$ decreased therefore the anti-corrosion property of the rust decreased. It indicated that alloy $\mathrm{Mn}$ suppressed the formation of stable phase $\alpha-\mathrm{FeOOH}$ while promoted the growth of active phase $\gamma$-FeOOH. As corrosion proceeded, the rust of samples containing more $\mathrm{Mn}$ was more likely to become less compact and less protective. As for the rust constituents of steel samples with different Ni contents, the rust layer was compose of similar phases as steels containing different contents of $\mathrm{Mn}$. As $\mathrm{Ni}$ content was raised, the quantities of both $\alpha-\mathrm{FeOOH}$ and $\mathrm{Fe}_{3} \mathrm{O}_{4}$ increased, while the quantities of $\gamma-\mathrm{FeOOH}$ got lower evidently. The content change indicated that $\mathrm{Ni}$ promoted the transfer of phases from less stable $\gamma$-FeOOH to more stable $\mathrm{Fe}_{3} \mathrm{O}_{4}$ or $\alpha-\mathrm{FeOOH}$. The ratio of $\alpha / \gamma^{*}$ increased as Ni content increased which indicated that $\mathrm{Ni}$ could enchance the stability and anti-corrosion performance of the rust. Electrochemical method is adopted to study the influence of alloys on the physical and chemical characteristics of rust layer as the corrosion of the steels in atmosphere is in accord with electrochemical corrosion law.
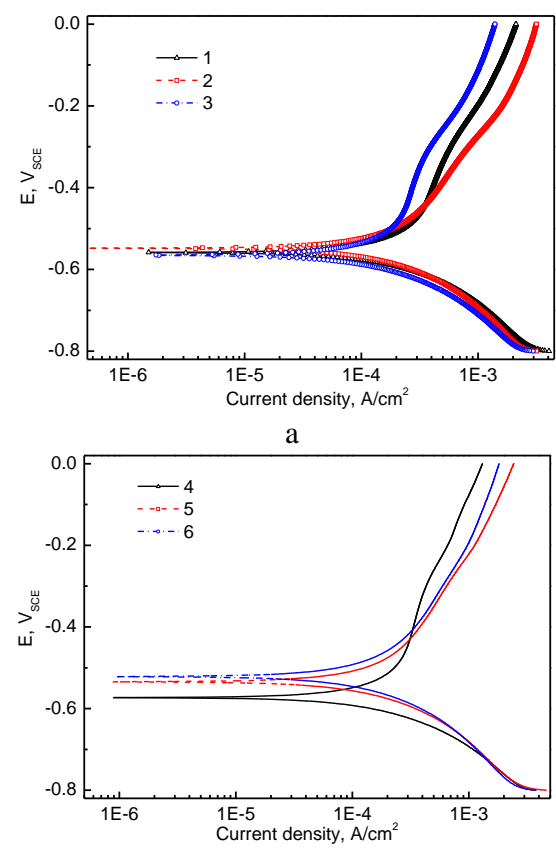

b

Fig. 7. Polarization curves of rusted experimental steels after 336 h corrosion: a-No. 1-3; b-No. 4-6

Fig. 7 shows the polarization curves of rusted steel samples corrupted for $336 \mathrm{~h}$ as a function of $\mathrm{Mn}, \mathrm{Ni}$ contents. Their $E_{\text {corr }}$ and $i_{\text {corr }}$ values are summarized in Table 2. As shown in Fig. 7 a, the content increase of Mn did not significantly alter the parameters of the polarization curve. However, as Ni contents increased, $E_{\text {corr }}$ shifted to the positive along with decreased $i_{\text {corr }}$ values indicating smaller corrosion rate as shown in Fig. $7 \mathrm{~b}$ and Table 2.

Table 2. Electrochemical parameters of steels

\begin{tabular}{|c|c|c|}
\hline No. & $E_{\text {corr }}, \mathrm{mV}_{\mathrm{SCE}}$ & $i_{\text {corr }}, \mu \mathrm{A} / \mathrm{cm}^{2}$ \\
\hline 1 & -559 & 41.8 \\
\hline 2 & -549 & 39.4 \\
\hline 3 & -565 & 42.4 \\
\hline 4 & -573 & 33.1 \\
\hline 5 & -535 & 23.2 \\
\hline 6 & -522 & 22.1 \\
\hline
\end{tabular}

As $\mathrm{Ni}$ increased from $0.42 \mathrm{wt} \%$ to $1.50 \mathrm{wt} . \%, E_{\text {corr }}$ moved to the positive region and $i_{\text {corr }}$ values decreased evidently, while as further increasing $\mathrm{Ni}$ content to $3.44 \mathrm{wt} . \%$, the trend was similar but the extent became weaker. The cathodic process of rusted steel samples is mainly controlled by the reduction of the rust in the presence of active phases in rust layer, while the anodic process is dominated by the dissolution process of steels. As the level of difficulty in cathodic reaction is due to the compact extent and the active phase content of rust layer, while the level of difficulty in anodic reaction is mainly due to active anodic area. For No.1-3 steel samples corrupted for $336 \mathrm{~h}$, the rust layer became a little bit more compact first then coarser (as shown in Fig. 3), meanwhile the quantity of active phase increased (such as $\gamma-\mathrm{FeOOH}$, 
as shown in Fig. 6), which was in accord with the slight parameters change of the polarization curve. The corrosion potential of rust layer of steels with more $\mathrm{Ni}$ content moved to the positive, and the anodic process was inhibited, which indicated the protective property of rust layer was enhanced. As Ni content increased, the extent of compactness of rust layer increased especially in the range from 0.42 wt.\% to 1.50 wt.\% (as shown in Fig. 4), while the content of active phase decreased obviously then slightly (such as $\gamma$-FeOOH, as shown in Fig. 6). The denser rust layer, decreased $\gamma$-FeOOH content and increased $\alpha$-FeOOH was responsible for the parameters change of the polarization curve. Namely, content increase of $\mathrm{Ni}$ from $0.42 \mathrm{wt} . \%$ to $1.50 \mathrm{wt} . \%$ played significant role in the extent of compactness, phase quantities and parameters of the polarization curve. Further increase the $\mathrm{Ni}$ content played similar role but the extent became smaller.

\section{CONCLUSIONS}

1. Mn contents have little impact on corrosion kinetics, however $\mathrm{Ni}$ decreased the corrosion rate of experimental steels evidently. The compactness of rust was reduced when Mn content exceeded $1.06 \mathrm{wt} . \%$. Ni facilitated the formation of compact rust.

2. The rust constitution of steel samples was mainly $\alpha-\mathrm{FeOOH}, \mathrm{Fe}_{3} \mathrm{O}_{4}$ and $\gamma$-FeOOH. The ratio of $\alpha / \gamma^{*}$ decreased as Mn content increased but increased as $\mathrm{Ni}$ content increased. Ni enchanced the stability of the rust however Mn was disadvantageous for stability of the rust.

3. The content increase of Mn did not evidently alter the parameters of the polarization curve. However, as $\mathrm{Ni}$ content increased, $E_{\text {corr }}$ shifted to the positive along with decreased $i_{\text {corr }}$ values indicating smaller corrosion rate especially in the content range from $0.42 \mathrm{wt} . \%$ to 1.50 wt. $\%$.

\section{Acknowledgments}

Authors appreciate supports offered by National Natural Science Foundation of China (No. 51304040) and Scientific Research Foundation of Ministry of Education in China (No. N150204008 and No. N110302001).

\section{REFERENCES}

1. Pérez, F.R., Barrero, C.A., García, K.E. Factors Affecting the Amount of Corroded Iron Converted into Adherent Rust in Steels Submitted to Immersion Tests Corrosion Science 52 (8) 2010: pp. 2582-2591.

2. Tamura, H. The Role of Rusts in Corrosion and Corrosion Protection of Iron and Steel Corrosion Science $50(7)$ 2008: pp. $1872-1883$.

3. Nishimura, T., Katayama, H. Clarification of Chemical State for Alloying Elements in Iron Rust Using a Binaryphase Potential-pH Diagram and Physical Analyses Corrosion Science 45 (5) 2003: pp. 1073-1084.
4. Strtmann, M., Bohnekamp, K., Ramchanran, T. The Influence of Copper upon the Atmospheric Corrosion of Iron Corrosion Science 27 (9) 1987: pp. 905 -926.

5. Zhang, Q.C., Wu, J.S., Wang, J.J., Zheng, W.L., Chen, J.G., Li, A.B. Corrosion Behaviour of Weathering Steel in Marine Atmosphere Materials Chemistry and Physics 77 (2) 2002: pp. 603-608.

6. Chen, Y.Y., Tzeng, H.J., Wei, L.I., Wang, L.H., Oung, J.C., Shih, H.C. Corrosion Resistance and Mechanical Properties of Low-alloy Steels under Atmospheric Conditions Corrosion Science 47 (4) 2005: pp. $1001-1021$. http://dx.doi.org/10.1016/j.corsci.2004.04.009

7. Prasad, S.N., Mediratta, S.R., Sarma, D.S. Influence of Austenitisation Temperature on the Structure and Properties of Weather Resistant Steels Materials science \& engineering A 358 (1-2) 2003: pp. 288-297.

8. Hao, L., Zhang, S.X., Dong, J.H., Ke., W. Atmospheric Corrosion Resistance of MnCuP Weathering Steel in Simulated Environments Corrosion Science $53(12)$ 2011: pp. 4187-4192.

9. Ke, W., Dong, J.H. Study on the Rusting Evolution and the Performance of Resisting to Atmospheric Corrosion for $\mathrm{Mn}-\mathrm{Cu}$ Steel Acta Metallurgica Sinica 46 (11) 2010: pp. 1365 - 1378 (in Chinese). http://dx.doi.org/10.3724/SP.J.1037.2010.01365

10. Gao, X.L., Zhu, M.Y., Fu, G.Q., Wang, F., Deng, Z.Y. Corrosion Behavior of Bridge Weathering Steels in Environment Containing $\mathrm{Cl}^{-1} \quad$ Acta Metallurgica Sinica 47 (5) 2011: pp. 520-527 (in Chinese).

11. Yamashita, M., Miyuki, Y., Kozakura, J., Mizuki, J., Uchida, H. In situ Observation of Initial Rust Formation Process on Carbon Steel under $\mathrm{Na}_{2} \mathrm{SO}_{4}$ and $\mathrm{NaCl}$ Solution Films with Wet/dry Cycles Using Synchrotron Radiation Xrays Corrosion Science 47 (10) 2005: pp. 2492-2498. http://dx.doi.org/10.1016/j.corsci.2004.10.021

12. Katayama, H., Noda, K., Masuda, H., Nagasawa, M., Itagaki, M., Watanabe, K. Corrosion Simulation of Carbon Steels in Atmospheric Environment Corrosion Science 47 (10) 2005: pp. 2599-2606.

13. Nishimura, T., Katayama, H., Noda, K., Kodama, T. Effect of Co and Ni on the Corrosion Behavior of Low Alloy Steels in Wet/dry Environments Corrosion Science 42 (9) 2000: pp. $1611-1621$. http://dx.doi.org/10.1016/S0010-938X(00)00018-4

14. Chen, X.H., Dong, J.H., Han, E.H., Ke, W. Effect of Ni on the Ion-selectivity of Rust Layer on Low Alloy Steel Materials Letters 61 (19-20) 2007: pp. 4050-4053.

15. Kimura, M., Kihira, H., Ohta, N., Hashimoto, M., Senuma, T. Control of $\mathrm{Fe}(\mathrm{O}, \mathrm{OH})_{6}$ Nano-network Structures of Rust for High Atmospheric-corrosion Resistance Corrosion Science 47 (10) 2005: pp. 2499-2509.

16. Kamimura, T., Hara, S., Miyuki, H., Yamashita, M., Uchida, H. Composition and Protective Ability of Rust Layer Formed on Weathering Steel Exposed to Various Environments Corrosion Science 48 (9) 2006: pp. 2799-2812. 